\title{
Non-conventional Power Plants in Aviation
}

\author{
Valerijs Voronovs ${ }^{1}$, Vladimirs Sestakovs ${ }^{2}{ }^{1-2}$ Institute of Aeronautics, Faculty of Transport and Mechanical \\ Engineering, Riga Technical University
}

\begin{abstract}
Power plants on the basis of heat engines except for reciprocating internal combustion engines and jet propulsion engines are classified by the authors of the paper as nonconventional ones. The article also presents the results of research carried out in this field by scientists of the Institute of Aeronautics of Riga Technical University. The article describes the two patents. The first patent to be considered was received for a rotary-piston engine, the second one - for the Stirling engine.
\end{abstract}

Keywords - Heat engine, oscillating internal combustion engine, rotary engine, stirling cycles.

\section{INTRODUCTION}

It is known that the first airplane in Russia and one of the first airplanes in the world that was built to the full size and possibly the first airplane in the world that presumably in 1885 took off with a man on board was A. Mozhaisky's airplane [1], [2]. As a power plant, Mozhaisky used two steam engines with a boiler made according to his own project because, in accordance with the inventor's calculations, the characteristics of the internal combustion engines available in those times were inferior to those of steam machines and, therefore, unsuitable for aircraft. Rapid development of internal combustion engines in those years, on the one hand, and the desire of many enthusiasts to get to the airspace, on the other hand, gave the Wright brothers an opportunity to create an airplane and make the first steady flight in the world in 1903. The airplane was equipped with an internal combustion engine of their own design. Since then the reciprocating internal combustion engine has been traditionally used in aviation. Today the reciprocating engine, which partly lost its popularity when jet propulsion engines started to be widely used in aviation, continues to hold the leading position in small-scale aviation. However, inventors from many countries are constantly trying to improve heat engines, including those intended for use in aviation. Nowadays there are quite a lot of sophisticated devices converting the reciprocal motion of the piston into the rotational motion of the engine shaft as one of the ways of increasing efficiency and reliability. This process occurs with varying success at different stages of scientific and technical progress in the field [3] - [13]. Thus, success in the area of steam engine construction promotes the possibility of using these engines in aviation from time to time. The number of attempts to launch the steam machine into the air after the Wright brothers' flight could hardly be counted. There are some successful projects of aircraft with such engines. Thus, already in 1933 an American company called "Besler" built and tested a steam airplane based on a power unit designed by the Doble brothers. The results of the tests were brilliant. This aircraft had considerable advantages over aircraft with reciprocating engines, which in those times were traditionally used in aviation. The advantages included: practical noiselessness, absence of vibrations and good efficiency at low speeds. At high altitudes, low temperature promoted condensation in the engine, thus improving its performance and decreasing the possibility of failures. The cost effectiveness was increased by using cheaper fuel. There are other examples, too. Today's scientific and technical progress in heat engineering inspires hope that the application of such engines in aviation will take on a new lease of life. Another direction in this area is related to attempts to substitute in aviation the reciprocating internal combustion engine with the Stirling engine. The Stirling engine belongs to the group of external combustion engines because its operation is based on the expansion of gas as a working fluid along with the increase in temperature [14].

Figure 1 below shows diagrams for an ideal Stirling cycle in the pressure-volume $(\mathrm{P}-\mathrm{V})$ and temperature-entropy (T-S) coordinates, and illustrates the relevant processes.
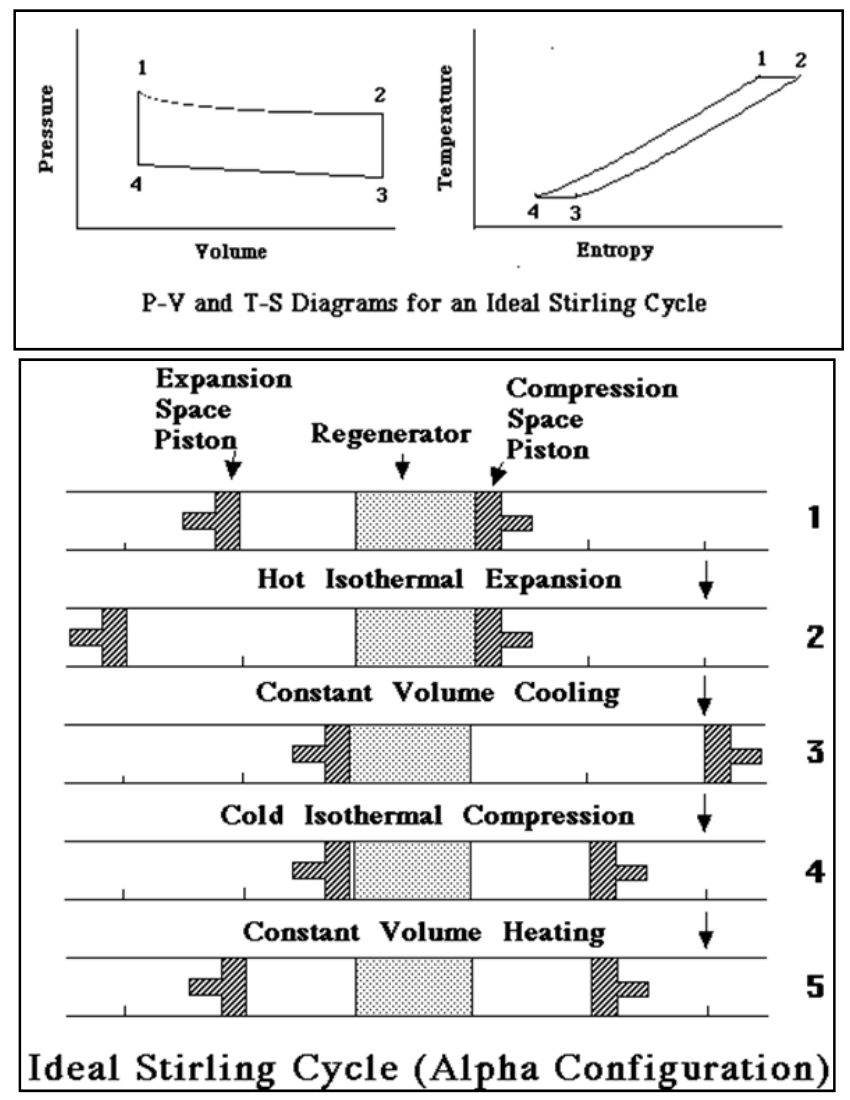

Fig. 1. Ideal Stirling cycle. 
In Fig. 1, the points marking the stages of engine operation are designated with numbers. The first stage (1-2) is related to isothermal gas expansion. The next stage (2-3) is related to cooling with a constant volume. Afterwards, stage (3-4) follows, which is the isothermal compression of the cooled gas. Finally, at stage (4-1) heating with a constant volume occurs. Effective work is carried out by the gas only at the first stage. All other stages occur at the expense of stored energy (usually the energy of the rotating wheel). After its invention in 1816, the Stirling engine survived the first period of widespread application at the beginning of the last century, after which it was practically forgotten. However, in recent years, it has received a lot of attention again in the most diverse areas of application. It is widely used for making toys and as teaching aids at schools and universities when studying thermodynamics. Development of science and technology resulted in the creation of new "ecological niches", in which the Stirling engine could be successfully used. Its advantages, which include high efficiency, reliability, unpretentiousness and the possibility of using environmentally safe sources of energy, allow expecting that the Stirling engine will be widely used in the future. A powerful fillip in this direction was given by NASA that conducted comparative evaluation of different types of heat engines to be used in space equipment [15]. The Stirling engine was recognized as the most promising engine due to its high efficiency and reliability. Thus, it is possible to say that the development of this engine is entering a new, promising stage. One of the directions of the research is the use of such engines in aviation. At the same time, the exploitation of steam power plants or Stirling engines in aviation can probably involve the application of hybrid power plants, i.e., combinations with electric, jet or other engines. Such examples can be found in different sources. For example, in 1965 in the USSR, aircraft IL-18П was developed on the basis of production aircraft IL-18. Because of its unique characteristics, the steam-turbine plant with uniflow steam heating developed at the Institute of Gas Dynamics Research named after Stechkin was used as a power plant. Steam heated in the steam heaters accelerated in the nozzles of the extension device, thus rotating the steam turbine; the shaft of the steam turbine in its turn drove the alternating current generator. Aircraft propellers were driven by four electric motors powered by the generator. Combined aviation engine by N.B. Bolotin (Application: 008125734/06, 24 June 2008) includes a turboprop gas turbine engine with an inner and outer shaft, compressor, main combustion chamber connected to the fuel pipe of the fuel pump as well as a turbine and jet nozzle. The Stirling engine is installed behind the turbine on the inner shaft of the engine; before the Stirling engine, an additional combustion chamber is placed which is connected with the additional fuel pipe of the additional fuel pump. The Stirling engine includes a working cylinder installed stream behind the additional combustion chamber and an expansion cylinder. The expansion cylinders are installed on the outer casing of the turboprop gas turbine engine. The invention aims at increasing the efficiency of the aviation engine along with a decrease in its weight, cost and improvement of its reliability. As a result of using the heat recovery of exhaust gases in the Stirling engine, the efficiency of the aviation engine increases by approximately $10-17 \%$. There are a lot of other versions of combined power plants to be used in aviation. However, it should be noted that none of them has been practically completed.

Most developments aiming to improve the efficiency and reliability of heat engines are related to the creation of heat engines of rotary type. The main components of the rotary engine schematic diagram include one or several rotors that make a rotational motion or ratchet relative to the casing. The latter, in its turn, can also rotate around a fixed axle. Due to the change in relative arrangement of rotors and casing, the volume of working fluid enclosed between these two components changes periodically in the process of rotation, which makes it possible to carry out the working cycle in the rotary engine that is similar to the working cycles of reciprocating engines.

The development of these engines is mostly hampered by difficulties in providing sealing for the work chambers between the rotor and the casing that leads to the decrease in their efficiency and reliability. Since F. Wankel and a number of other inventors offered several sealing circuits, studies on rotary engines have become one of the most prospective directions in the field of heat engines [6]. At present, engines of this type, with an exception of Wankel's engines, are not serially produced despite a vast variety of circuits and constructions supported by thousands of invention patents and certificates issued to scientists from different countries. There is a generally accepted classification of inventions and patents in the area of rotary engines [16]. It includes practically all possible types of engine designs of the given type. Analysing the variety of these designs, it is possible to say that the construction diagrams of some subclasses do not help to solve the problems posed by the authors at the stage of development.

\section{RESEARCH ON HEAt ENGINES By the SCIENTISTS OF RIGA TECHNICAL UNIVERSITY}

For many years the Institute of Aeronautics (the Institute of Aviation until 2012) of Riga Technical University has been carrying out research on developing new construction diagrams of heat engines based on Stirling's principles and of rotary type that can be used in aviation [17].

The creation of new types of engines and their application in aviation are expedient only in the case when it is possible to obtain at least one of the following advantages in comparison with the RE:

- increase in the construction compactness along with an increase in overall volume utilization factor for the arrangement of work compartments;

- increase in the engine speed rate by increasing the number of revolutions made by power takeoff shaft rotors in comparison with the number of revolutions of $\mathrm{RE}$ crankshafts. It can be achieved by removing a valve gas distribution mechanism and by applying such a 
construction diagram that allows avoiding the appearance of alternating inertial forces;

- simplification of the whole construction in comparison with RE.

The advantages over the RE should be achieved without reducing reliability, service life and fuel efficiency.

We offer two engine designs supported by invention patents that were developed by scientists from Riga. One of them belongs to rotary engines, the other to the class of Stirling engines.

\section{A. Oscillating Internal Combustion Engine}

The engine was developed for a single-engine aircraft; it was tested on the model and in design projects, including graduation projects by the students of the Institute of Aviation.

The engine diagram and operating principles are presented in Fig. 2 and Fig. 3.

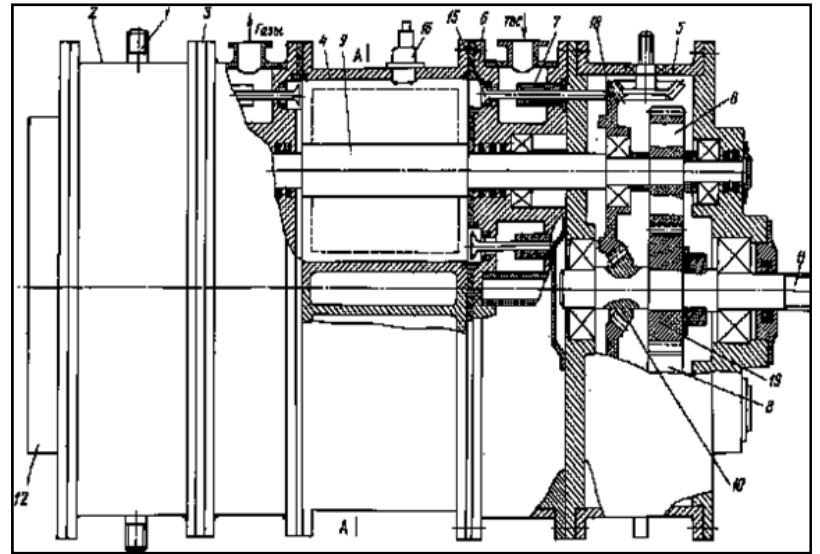

Fig. 2. Oscillating Internal Combustion Engine diagram.

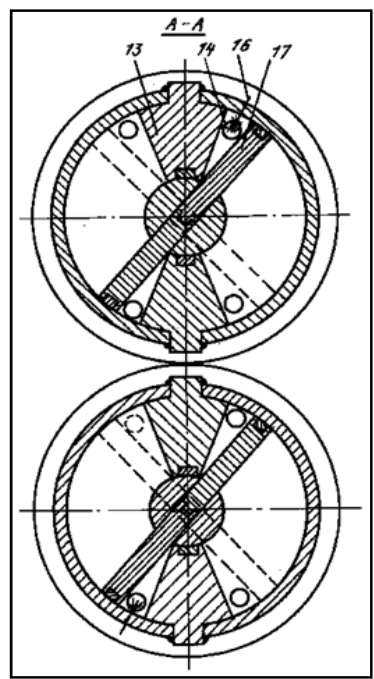

Fig.3. Oscillating Internal Combustion Engine operating principles.

The engine consists of two casings that form a single block; each of them has a shaft (9) with blades (17) inside. The shafts perform oscillatory motions under the effect of gases appearing as a result of the combustion of air-fuel mixture in the combustion chambers placed among the blades and partitions (13). The ignition in blocks in the combustion chambers of the same name (14) is provided with a $90^{\circ}$ shift. Oscillatory motions of the shafts are summed up through the overrunning clutches (8) and at the exit of the engine casings are transmitted to the two shafts (12) performing rotational motions in opposing directions on different sides of the engine, which also excludes the idle running of the blades. Taking into consideration the facts that oscillations in each block occur in antiphases and that gear wheels and shafts in the accessory boxes $(2,5)$ rotate in different directions, there will be no gyroscopic and inertial moments and vibrations. Besides, the high level of compactness of the given engine design makes it possible to expect a substantial improvement of engine reliability indices and specific performance (Nsp, Csp, Psp - specific power, specific fuel consumption, specific weight, etc.). All this allows stating that, in comparison with $\mathrm{RE}$, the given design makes it possible to produce the oscillating engine without reducing its reliability, service life and fuel efficiency. It is possible to learn more about the design and operation of the engine in [18].

Implementation of the above-mentioned requirements in the proposed engine design is provided below.

I. Improvement of compactness and small specific weight are achieved:

1. at the expense of increasing engine overall volume utilization factor without any additional assemblies, systems and walls, as well as by increasing the coefficient characterizing the ratio of engine capacity to its overall volume;

2. by increasing the speed rate, which is determined by the number of revolutions per minute and by the speed of rotor peripheral points relative to the casing. This limitation is related to the increase in inertial forces.

II. Sealing of work compartments is achieved with the help of an oil film necessary for avoiding dry friction and reducing losses in trimming, which promotes the increase in sealing efficiency. When the engine is started and during the warmup, the presence of the oil film has a relatively small influence on the volume of gas leaks; however, when it has been formed, its influence on sealing efficiency is very considerable. The wear degree of the wearing pieces can be reduced by limiting the speed of rotors up to $25-30 \mathrm{~m} / \mathrm{sec}$, which corresponds to the maximum speed of pistons in modern reciprocating engines.

Thus, the solution to the problem of sealing in the given engine is achieved at the expense of effective lubrication and rotor speed limiting.

III. Simplification of the whole construction in comparison with RE. Exactly this solution to the problem is the main advantage of the proposed engine design.

There is also a modified design of the given engine. This is a two-shaft engine with axle screw propellers rotating in opposing directions on one side of the engine. Such an engine is based on the mirror part of the cylinder of aviation engine ASH-62. Its design power is 900 horse power. 


\section{B. Developments Related to the Stirling System}

Most projects in this direction were carried out in SolidWorks programme. The developments were aimed at creating a device that operates by using Stirling principles and can convert energy obtained as a result of temperature difference and use this energy for increasing the efficiency of other systems: electric and thermal ones. As it has been noted above, presently there is a large number of developments of this type; however, the authors have managed to develop and test their own unique device. Its essence is captured in the following [9]:

The solution to the problem was achieved by creating a new modification of Beta type Stirling engine, where the unidirectional flow of working gas was provided. To achieve this goal, the flow channels were created at the top and at the bottom of the cylinder in order to provide a gas flow from the volume between the upper piston and the lower piston, and between the upper piston and the cylinder head. For the Stirling engine, it is important to have as high working gas temperature difference as possible; and in our type of engine it is provided by organizing separate unidirectional flows through the heater and the cooler. Owing to such a design, the working gas takes heat energy from the cylinder head and cylinder walls quicker and smoother providing a faster and larger increase in pressure. Maximum heat exchange is achieved after top dead centre, and it helps to increase the engine power output.

The flow channels at the bottom of the cylinder are connected with the top of the cylinder to provide the flow of working gas from the space between the two pistons back to the top of the cylinder (the schematic picture of the engine is presented in Fig. 4). Those channels also act as working gas coolers and can be equipped with a valve that provides a unidirectional flow and separates the cooler volume from the heater volume, thus decreasing the so-called dead volume.

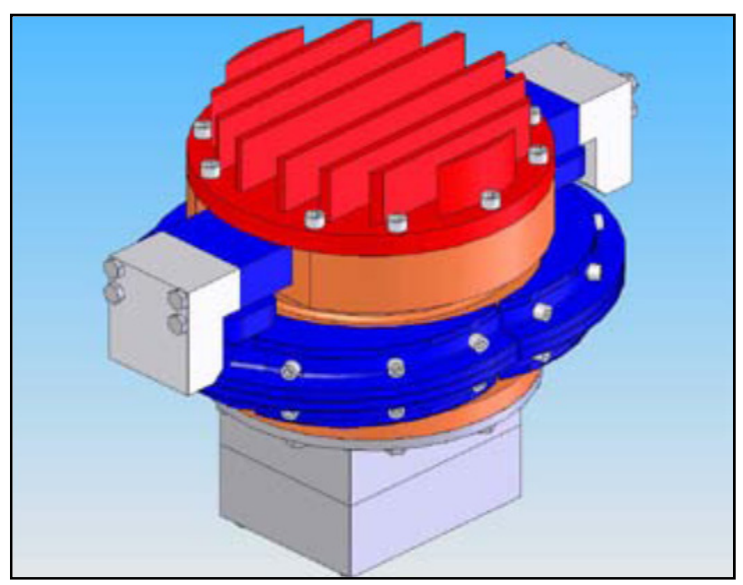

Fig. 4. Schematic picture of the engine.

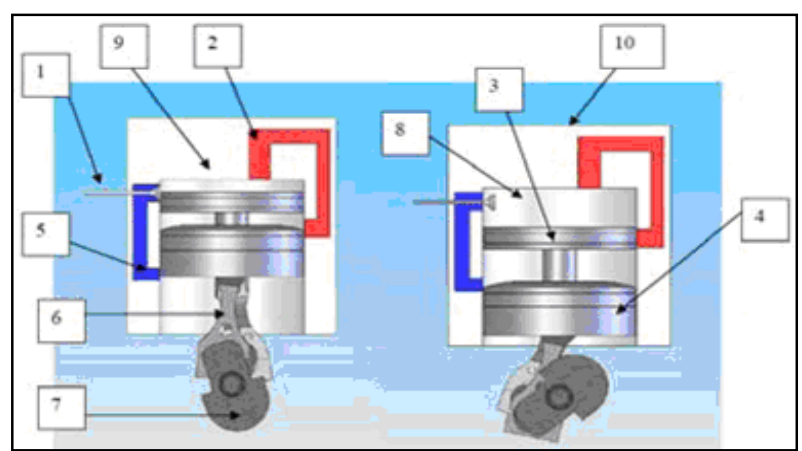

Fig. 5 . 1 - valve; 2 - heater; 3 - upper piston; 4 - lower piston; 5 - cooler; $6-$ connecting rods; 7 - crankshaft; 8 - cylinder; 10 - cylinder head; 11 cylinder block.

Dead volume is defined as a total void volume in the Stirling engine. In general, the dead volume is referred to as a volume of working fluid contained in the total dead space of the engine, including the regenerator and transfer port. In normal Stirling engine design practice, the total dead volume is approx. $58 \%$ of the total volume. The dead volume will decrease both the engine network and the thermal efficiency, and will increase both the external heat input and output. However, the real engine must have some unavoidable dead volume [1]. In our modification, we can reduce the amount of dead volume by approx. $50 \%$ by implementing a valve. The developed engine must at least consist of a crankshaft or a crankshaft mechanism, at least one cylinder, at least one cylinder head, connecting rods of the crankshaft mechanism, a heater, a cooler, at least two pistons in each cylinder, piston pins, a valve mechanism and overflow channels (Fig. 5). The cylinder has two pistons in a reciprocating motion along the cylinder that are mutually offset. The offset is needed to create two variable volumes - the volume between the pistons and the volume between the upper piston and the cylinder head. The upper piston (displacer piston) and the lower piston (power piston) motions in the cylinder are the same as in the classical Beta type Stirling engine.

In aviation, such a device can be used only as part of a hybrid power plant, i.e., in combination with the internal combustion engine or jet propulsion engine.

\section{CONCLUSIONS}

The article shows that non-conventional thermal systems, such as cogeneration plants, Stinger engines, rotary engines, acquire a new lease of life at the present stage of scientific and technical progress and can be used in the most varied areas of national economy demonstrating higher efficiency and reliability in comparison with conventional thermal systems. Aviation, where such devices can be used in hybrid power plants, may become one of the spheres of application. The article also presents the main directions of research and results obtained by scientists from Riga working in this area. 


\section{ACKNOWLEDGMENTS}

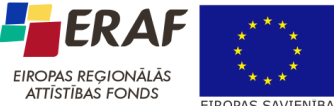

IEGULDİJUMS TAVĀ NĀKOTNĒ

The research project has been supported by the ERAF and the presented material is part of the project "Modelling and Research of Effective Small Size Heat Engine Gas Processes"

No.2010/0235/2DP/2.1.1.1.0/10/APIA/VIAA/093, RTU PVS ID 1536

\section{REFERENCES}

[1] V. B. Savrov, Istoria konstrukcij samoletov v SSSR, 3-e izdanie. Moskva: Mashinostroenie, 1985.

[2] V. A. Krylov, Aleksandr Fedorovic Mozajskij. Zizn zamecatelnyh ludej. Moskva: Molodaja Gvardija, 1951.

[3] C. D. West, Theoretical basis for the Beale number. In: Proceedings of the 16th Intersociety Energy Conversion Engineering Conference, Paper 819787. Atlanta: American Society of Mechanical Engineers, 1981.

[4] W. Winkler and H. Lorenz. "Design studies of mobile applications with SOFC-heat engine modules", Journal of Power Sources, vol. 106, Issues 1-2, pp. 338-343, April 2002. [Online]. Available: http://www.sciencedirect.com/ [Assessed Jan.19, 2014]

[5] D. A. Aramtummaphon. "Study of the feasibility of using heat energy from producer gas for running stirling engine by steam as working Fluid." Master thesis, King Mongkut's University of technology Thonburi, Thailand, 1996.

[6] F. Feller and M. I. Mech, The 2-Stage Rotary Engine-A New Concept in Diesel Power by Rolls-Royce, vol. 185, pp. 139-158, Proceedings 1970-71, London, The Institution of Mechanical Engineers, 1971.

[7] K. Perkins, Osprey Automotive. London, UK, 1991.

[8] K. E. Ludvigsen, Wankel Engines A to Z. New York, USA: Ludvigsen Publication, 1973.

[9] J. K. Yamaguchi, The Mazda RX-8: World's First 4-door, 4-seat Sports Car Plus Complete Histories of Mazda Rotary Engine development and Rotary Racing Around the World. Ring ltd, 2003.

[10] M. A. Markman, Y. I. Shmatok and V. G. Krasovkii, Eksperimentalnoe issledovanie malomosnogo dvigatela Stirlinga. Geliotekhnika, 1983, pp. $19-24$.

[11] B. Orunov, V. S. Trukhov and I. A. Tursunbaev, Rascet parametrov simmetricnoj rombiceskoj privodom dla odnocilindrovym dvigatelem Stirlinga.. Geliotekhnika, 1983, pp. 29-33.

[12] S. Abdalla and S. H. Yacoub, Feasibility prediction of potable water production using waste heat from refuse incinerator hooked up at Stirling cycling machine. Desalination, 1987, pp. 491-500. http://dx.doi.org/10.1016/0011-9164(87)90118-4

[13] N. Nakajima, K. Ogawa and I. Fujimasa, Study on microengines miniaturizing Stirling engines for actuators and heatpumps: Micro Electro Mechanical Systems, Feb.20-22, 1989. [Online]. Available http://ieeexplore.ieee.org/ [Accessed: Jan. 15, 2014].

[14] A. J. Organ, Thermodynamics and Gas Dynamics of the Stirling Cycle Machine. Cambridge, UK: Cambridge University Press, 1992.

[15] N. P. Nightingale, NASA Automotive Stirling Engine MOD II Design Report. Cleveland, USA: NASA, 1986.
[16] R. Gheith, F. Aloui and S. B. Nasrallah, "Optimization of Stirling Engine performance based on Experimental Design approach," International Journal of Energy Research, vol. 37 issue 12, pp. 1519$1528,2013$. http://dx.doi.org/10.1002/er.2964

[17] V. Voronov, "Kolebatelnyj dvigatel vnutrennego sgorania," Patent in Russia 2247248 C2, September 5, 2002.

[18] I. Blumbergs and V. Uchakov, Specifics of Stirling Engine with Recuperation heat Exchanger: The 20th International Scientific and Technical Conference on Transport, Road-Building, Agricultural, Hoisting \& Hauling and Military Technics and Technologies, pp. 17-19, July 27-29, 2012, Varna, Bulgaria.

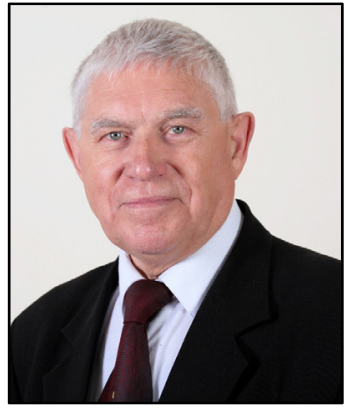

Valerijs Voronovs is an Engineer at the Institute of Aeronautics of Riga Technical University, Latvia. Education: Riga Institute of Civil Aviation Engineers, Mechanical Engineer (1967). After graduation he worked in various engineering positions in the aviation enterprises in Latvia. In 1972 he passed a flight engineer test on the relearning of the Tu-134. In this capacity he logged more than 2,000 hours. He has an award "Excellence in Aeroflot". He has been working on various inventions in the field of aircraft maintenance. $\mathrm{He}$ has several inventor's certificates and 1 patent.

His fields of research: aviation, rotary-piston engines.

Address: Institute of Aeronautics, Faculty of Transport and Mechanical Engineering, Riga Technical University, Lomonosova 1A, k-1, Riga, LV1019, Latvia. Phone: +37167143157.

E-mail: aerti@rtu.lv, voronov@inbox.lv

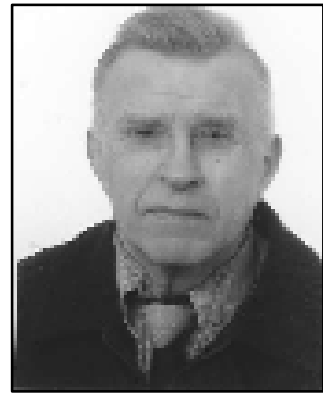

Vladimirs Sestakovs graduated in Technical Aircraft and Engine Exploitation from Riga Institute of Civil Aviation Engineers in 1963. $\mathrm{He}$ is a Professor, Doctor of Engineering Sciences (Dr.habil.sc.ing.).

Present job: Head of the Aircraft Maintenance Division, Aviation Institute, Riga Technical University. Education: Riga Institute of Civil Aviation Engineers, Mechanical Engineer (1963); Leningrad Civil Aviation Academy, Doctoral Degree in Aviation (1984), Doctor Habilitus Degree in Engineering (1992).

$\mathrm{He}$ is a Full Member of the International Academy of Ecology and Safety of Vital Functions (1994), International Academy of Ecology and Life Protection Sciences (Academician), RTU Promotion Council "Air Transport Operations", Latvian Association of University Professors. He has 242 publications, 25 teaching aids, including 3 textbooks (in co-authorship), 2 monographs, 9 patents.

His fields of research: aviation, rotary-piston engines, professional air transport exploitation, flight safety, ecology and life protection sciences, ecologically pure non-traditional kinds of transport.

Address: Institute of Aeronautics, Faculty of Transport and Mechanical Engineering, Riga Technical University, Lomonosova 1A, k-1, Riga, LV1019, Latvia. Phone: +371 67089959 .

E-mail: aerti@rtu.lv, shestakov@inbox.lv 